\title{
Лечение предсердных тахикардий у лиц с врожденными пороками сердца
}

\author{
Стычинский А. С., Альмиз П. А., Топчий А. В., Плиска Н. В., Поканевич А. В., \\ Лозовой О.А. \\ ГУ «Национальный институт сердечно-сосудистой хирургии имени Н. М. Амосова НАМН Украины» (Киев)
}

\begin{abstract}
Цель работы - изучить особенности катетерного лечения предсердных тахикардий у лиц с врожденными пороками сердца. В отделе электрофизиологии и рентген-хирургических методов лечения аритмий сердца в период с января 2008 по июль 2018 года произведено катетерное лечение предсердных тахикардий у 44 пациентов с врожденными пороками сердца. Непосредственная эффективность составила 95\%, рецидивы в отдаленные сроки имели место в $14 \%$ случаев. Анализ материала показал, что почти у одной трети пациентов имелась комбинация аритмий с различным характером циркуляции возбуждения.
\end{abstract}

Ключевые слова: предсердные тахикардии, врожденные пороки сердиа, катетерные абляции.

Благодаря успехам в кардиохирургии, достигнутым за последние десятилетия, число выживающих с врожденными пророками сердца (ВПС) в общей популяции увеличивается с каждым годом. Суправентрикулярные тахикардии (СВТ) встречаются у лиц с ВПС с частотой 10-20\% в зависимости от сложности ВПС, включенного в исследование, и длительности периода наблюдения [1]. Возникновение этих аритмий повышает риск развития недостаточности кровообращения, инсультов, внезапной сердечной смерти. Наиболее частыми видами СВТ при ВПС являются предсердные тахикардии (ПТ) с механизмом макро-риентри [1, 4]. Данные обзора 2014 года свидетельствуют о том, что непосредственная эффективность катетерного устранения предсердных тахикардий находится в пределах 65-96\% (в среднем 81\%), а частота рецидивов аритмии в течение 5-летнего срока составляет 34-54\% [4]. Таким образом, мы видим, что и непосредственные, и отдаленные результаты катетерного лечения ПТ у лиц с ВПС хуже, чем при лечении других видов СВТ в отсутствие сопутствующей структурной патологии сердца.

Цель работы - анализ имеющегося опыта катетерного лечения предсердных макро-риентри у взрослых пациентов с ВПС.

Материалы и методы. В работе использованы данные 50 процедур по катетерному устранению ПТ у 44 больных с ВПС, произведенных в период с 1.01.2008 по 1.07.2018 г. У 26 пациентов имелась устойчивая аритмия с морфологией зубца Р, характерной для истмус-зависимого трепетания предсердий (ТП) с циркуляцией возбуждения против часовой стрелки; у 18 различные варианты морфологии предсердного зубца. У 4 пациентов на момент процедуры был синусовый ритм, аритмия у них была индуцирована стимуляцией.
Устранению аритмии предшествовал этап электрофизиологической диагностики, при которой определялся механизм аритмии, место расположения субстрата аритмогенеза, а также участки для радиочастотного воздействия. Применялись методики активационного и субстратного картирования в сочетании с различными режимами стимуляции (расе mapping, определение постстимуляционного интервала и др.).

Результаты и их обсуждение. При эндокардиальном картировании ПТ с циркуляцией возбуждения через кавотрикуспидальный перешеек была установлена у всех пациентов с морфологией зубца Р, характерной для типичного ТП, и у 4 - с нехарактерной морфологией. В результате нанесения аппликаций в кавотрикуспидальном перешейке синусовый ритм был восстановлен в 23 из 30 случаев; в 7 случаях произошло изменение цикла тахикардии и морфологии зубца Р. Дальнейшее картирование показало изменение фронта распространения возбуждения: в 6 случаях циркуляция происходила вокруг рубца после атриотомии, в одном - вокруг обширной зоны с низкоамплитудными электрограммами в переднелатеральной зоне правого предсердия. Нанесение линии аппликаций между рубцом и кольцом трикуспидального клапана привело к прекращению аритмии. У 6 из 23 пациентов, у которых синусовый ритм был восстановлен после нанесения аппликаций в кавотрикуспидальном перешейке, частой стимуляцией впоследствии была индуцирована тахикардия с другой морфологией зубца Р и с циркуляцией возбуждения вокруг рубца после атриотомии, а у одного - фокальная тахикардия из устья коронарного синуса. Из 14 пациентов, у которых первоначально было диагностировано не истмусзависимое ТП, в 12 случаях циркуляция возбуждения 
происходила вокруг рубца после атриотомии, в одном случае - вокруг обширной зоны с низкой электрической активностью и в одном случае - вокруг заплаты на межпредсердной перегородке. В результате абляции тахикардия была устранена у 13 из 14 пациентов этой подгруппы. После восстановления синусового ритма частой стимуляцией в 3 случаях удалось индуцировать неустойчивую фибрилляцию предсердий и в одном - истмус-зависимое ТП. У этого пациента был создан блок проведения через кавотрикуспидальный перешеек.

В результате катетерной процедуры аритмия была устранена у 43 (98\%) из 44 пациентов. Следует отметить, что при нанесении аппликаций в кавотрикуспидальном перешейке в 7 (23\%) из 31 случая добиться создания блока проведения удалось только при применении катетеров с наружным охлаждением; при устранении не истмус-зависимых ПТ необходимость в применении охлаждаемых катетеров возникла в 6 (22\%) из 27 случаев.

Во всех случаях до- и послеоперационные осложнения отсутствовали.

В отдаленные сроки рецидивы аритмии наблюдались у 6 (15\%) пациентов. В 3 случаях это был рецидив аритмии, которую устраняли (истмус-зависимое ТП - 2, ПТ с циркуляцией вокруг послеоперационного рубца - 1), в 3 - аритмия с другим характером распространения возбуждения. Все эти аритмии были окончательно устранены при повторных процедурах.

Анализ приведенных данных показывает, что наиболее распространенным видом ПТ у лиц с ВПС является истмус-зависимое ТП. Эту тенденцию отмечают и другие исследователи $[3,5]$. Комбинация различных видов риентри, встретившаяся у $32 \%$ наших пациентов, характерна для ПТ после коррекции ВПС [3-5]. Непосредственная эффективность катетерного устра- нения предсердных макро-риэнтри при ВПС достаточно высока. Она составила $100 \%$ для истмус-зависимого ТП и 96\% - для не истмус-зависимых ПТ. В то же время так же высока и частота рецидивов в отдаленные сроки. Поэтому после устранения исходной аритмии необходима тщательная проверка возможности возникновения другой аритмии. Вопрос о целесообразности профилактики потенциально возможных аритмий (например, создание блока в кавотрикуспидальном перешейке у тех, у кого имелась лишь ПТ с циркуляцией вокруг рубца после атриотомии) нуждается в рассмотрении.

Выводы

1. Катетерное лечение ПТ у лиц, которым производилось хирургическое лечение ВПС, является эффективным и безопасным методом.

2. После хирургической коррекции ВПС возможно появление комбинации нескольких вариантов предсердных макро-риентри.

\section{Литература}

1. 2015 ACC/AHA/HRS Guideline for the management of adult patients with supraventricular tachycardia: Executive summary. J. Am. Coll. Cardiol. 2015.

2. PACES/HRS Expert consensus statement on the recognition and management of arrhythmias in adult congenital heart disease. Canadian J. Cardiol. 2014;30:e1-e 63.

3. Wasmer K, Kube J, Dechering VG et al. Isthmus-dependent right atrial flutter as the leading cause of atrial tachycardias after surgical atrial septal defect repair. Int.J.Cardiol. 2013;168:2447-52.

4. Lobo RG, Griffith M, De Bono J. Ablation of arrhythmias in patients with adult congenital heart disease. Arrhythm. Electrophysiol. Rev. 2014;3:36-39.

5. Arrhythmias in congenital heart disease: a positional paper of the EHRA, AEPCC, ESC, working group on congenital heart disease, endorsed by HRS,PACES, APHRS and SOLAECE. Europace. 2018;20:1719-20.

\title{
Management of Atrial Tachycardias in Patients with Congenital Heart Disease
}

\author{
Stychynskyi A. S., Almiz P. A., Topchii A. V., Plyska N. V., Pokanevitch A. V., Lozovyi O. A.
}

National M. M. Amosov Institute of Cardiovascular SurgeryNational Academy of Medical Sciences of Ukraine (Kyiv)

Atrial tachyarrhythmia is observed in $10 \%$ to $20 \%$ of adult congenital heart disease (CHD) and is associated with high morbidity, impaired quality of life and mortality. The purpose of the study is to describe atrial tachycardia (AT) type, ablation success and follow-up. Material and methods: a total of 50 ablations in 44 CHD patients were reviewed. Results: cavotricuspid isthmus - dependent flutter (CTI-F) was found in 30 patients, other types of reentrant AT mostly scar-related (Non CTI-F) - in 14 patients. In patients with CTI-F, as a result of ablation, sinus rhythm was restored in 23 of 30; in 7 patients CTI-F was transformed into another type of atrial reentry. Of 23 patients with restored sinus rhythm, 6 patients experienced another type of atrial reentry induced by rapid pacing. Non CTI-F terminated during ablation and was non-inducible in 13 of 14 patients; in 3 patients rapid pacing induced non-sustained atrial fibrillation and in one - CTI-F, which was successfully eliminated. Overall, acute success rate was $98 \%$, with $100 \%$ for CTI-F and $96 \%$ for non CTI-F.

There were 6 recurrences during the follow-up: in 3 cases it was AT previously ablated; in 3 cases - a different type of AT. All of them were successfully ablated after the second procedure.

AT catheter ablation in patients with CHD is feasible, safe, with high success rate.

Key words: atrial tachycardia, congenital heart disease, catheter ablation. 


\section{Лікування передсердних тахікардій у пацієнтів із вродженими вадами серця}

Стичинський О. С., Альміз П. О., Топчій А. В., Плиска Н. В., Поканєвич А. В., Лозовий О. А. ДУ «Національний інститут серцево-судинної хірургії імені М. М. Амосова НАМН України» (Київ)

Передсердні тахікардії спостерігаються у 10-20\% дорослих із вродженими вадами серця і асоціюються з високою захворюваністю, зниженням якості життя та підвищенням смертності. Мета дослідження - дослідити типи передсердних тахікардій, успішність абляції та післяопераційні результати. Матеріали та методи. Виконано загалом 50 абляцій у 44 пацієнтів із вродженими вадами серця. Результати. Залежне від кавотрикуспідального істмусу тріпотіння буле виявлене у 30 пацієнтів, інші види передсердних тахікардій за механізмом ріентрі, переважно пов’язані з рубцем, - у 14. У пацієнтів з істмус-залежним тріпотінням у результаті абляції синусовий ритм було відновлено у 23 із 30; у 7 істмус-залежне тріпотіння трансформувалося в інший вид передсердного ріентрі. Із 23 пацієнтів зі збереженим синусовим ритмом у 6 інший вид передсердної тахікардії був індукований стимуляцією. Не істмус-залежне тріпотіння було припинено під час абляції та не індукувалося у 13 із 14 пацієнтів; у 3 пацієнтів стимуляцією було викликано нестійку фібриляцію передсердь і в одного - істмус-залежне тріпотіння, яке було успішно усунуто. Загальна успішність процедур склала $98 \%$ із $100 \%$ при істмус-залежному тріпотінні та 96\% при не-істмус-залежному.

При спостереженні у післяопераційний період було 6 рецидивів:у 3 випадках це були ті ж аритмії, які усувалися, у 3 випадках - інші види ПТ. Всі були успішно усунені під час другої процедури.

Катетерна абляція ПТ у пацієнтів із ВВС - дієве, безпечне і високоефективне втручання.

Ключові слова: передсердні тахікардї, вроджені вади серия, катетерна абляція. 